\title{
UMA APLICAÇÃO DE MODELAGEM DO CICLO HIDROLÓGICO E IMPACTOS DO AUMENTO DA CONCENTRAÇÃO DE $\mathrm{CO}_{2}$ ATMOSFÉRICO NA AMAZÔNIA
}

\section{Yuri Silva de Souza ${ }^{1}$ David Montenegro Lapola ${ }^{2}$}

Resumo - O presente trabalho busca validar um modelo de balanço hídrico para permitir sua aplicabilidade no bioma Amazônico, em linha com o projeto Amazon-FACE (free-air $\mathrm{CO}_{2}$ enrichment), buscando melhorar o entendimento dos efeitos do aumento de $\mathrm{CO}_{2}$ na dinâmica hídrica desse bioma. O modelo a ser utilizado trata-se do submodelo de balanço hídrico do modelo CPTEC-Potential Vegetation Model 2 (PVM2). A avaliação deste submodelo ocorrerá através dos protocolos desenvolvidos pelo International Land Model Benchmarking Project (I$\angle A M B)$. Para avaliar o efeito do aumento de $\mathrm{CO}_{2}$ no bioma amazônico será adicionado ao modelo 200ppmv de $\mathrm{CO}_{2}$ a mais que a concentração atual. As variáveis a serem avaliadas serão água no solo, evapotranspiração e escoamento superficial. O projeto ainda está em andamento, mas apresenta alguns resultados preliminares referentes a atualização do modelo hídrico, sendo a aplicação e validação os próximos passos.

Palavras-chave: Mudanças climáticas; Modelagem hídrica; Floresta Amazônica; Amazon-FACE.

\footnotetext{
${ }^{1}$ Graduando do Curso de Ecologia/Universidade Estadual Paulista/Ecologia-IB, Brasil. E-mail: yurieco@rc.unesp.br.

2 Doutor em Modelagem do Sistema Terrestre/Docente e pesquisador/Universidade Estadual Paulista/Ecologia-IB, Brasil. E-mail: dmlapola@rc.unesp.br.
} 